JEEP 2011, 00005 (2011)

DOI: $10.1051 /$ jeep/201100005

(C) Owned by the authors, published by EDP Sciences, 2011

\title{
Study of solid-liquid and solid-vapour equilibria in tenatoprazole potassium salt/solvents systems
}

\author{
G. Tauvel, Y. Cartigny, M. Sanselme, and G. Coquerel
}

SMS Laboratory, EA 3233 IMR4114, University of Rouen, F-76821 Mont Saint Aignan Cedex, France

\begin{abstract}
Tenatoprazole, 5-methoxy-2-\{[(4-methoxy-3,5-dimethyl-2-pyridyl)-methyl]-sulfinyl $\}$-imidazo[4,5-b]-pyridine, is a proton pump inhibitors (PPI). A conglomerate screening of $( \pm$ ) tenatoprazole by crystallisation of various salts and solvates led to the detection of potassium salts dihydrate and efflorescent ethanol and methanol solvates giving a full chiral discrimination in the solid state. The aim of this study was to determine solid-liquid and solid-vapour equilibria of the system [tenatoprazole potassium salt / methanol / ethanol] by combining structural, thermal and dynamic sorption / desorption data. The isothermal section at $20^{\circ} \mathrm{C}$ of this system was determined by using DITA (Discontinuous Isoperibolic Thermal Analysis) measurements and structural studies (in situ XRPD). Despite extensive structural similarities the study performed here suggests the existence of a partial solid solution between methanol and ethanol solvates.
\end{abstract}

\section{Introduction}

Tenatoprazole, 5-methoxy-2-\{[(4-methoxy-3,5-dimethyl2-pyridyl)-methyl]-sulfinyl $\}$-imidazo-[4,5-b]-pyridine (figure 1), is a proton pump inhibitors (PPI) and belongs to the class of anti ulcer agents, acting by inhibition of gastric acid secretion, like other 'prazole' derivatives (i.e. omeprazole) [1].

Tenatoprazole is a chiral molecule: the stereogenic centre is located on the sulphur atom of the sulfinyl group. Moreover, in its neutral form, it crystallises as a racemic compound.

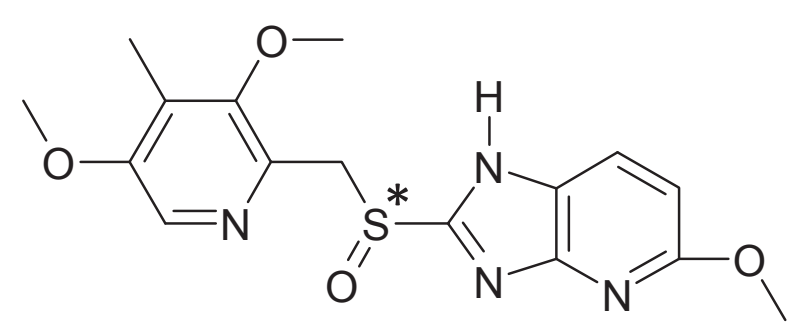

Fig. 1. Chemical formula of the tenatoprazole

The preparative resolution of the tenatoprazole by using preferential crystallisation has been carried out [2-3]. The preliminary step of this achievement was a conglomerate screening (salts, solvates). It led to the detection of potassium salts providing a full enantiomeric discrimination: dihydrate, ethanol and methanol solvates. The alcohol solvates of the S-tenatoprazole potassium salt ((S)-TUK hereafter) were crystallised in solution but they present an efflorescent character: under atmospheric condition these solids evolve spontaneously towards the dihydrate. The aim of this study was to highlight the thermodynamic relationship between the ethanol and methanol solvates. The structural, thermal and dynamic sorption / desorption analyses allowed the determination of solid-liquid and solid-vapour equilibria of the system [(S)-TUK / Methanol / Ethanol].

\section{Materials and methods}

\subsection{Single Crystal X-Ray diffraction}

Single crystals were coated with glue, and then, stuck on glass fibers and mounted on the full three circles goniometer of a Bruker SMART APEX diffractometer $(\mathrm{MoK} \alpha, \lambda=0.71073 \mathrm{~A}$ ) with a $\mathrm{CCD}$ area detector (see [4] for more details). 


\subsection{X-Ray Powder Diffraction (XRPD)}

In situ XRPD analyses (on suspensions) were performed, with $\mathrm{NaCl}$ as an internal standard, on a D8 diffractometer (Bruker) equipped with a LynxEye detector.

\subsection{Dynamic Vapour Sorption}

A Dynamic Vapour Sorption experiment consists in monitoring the mass variation of a solid conditioned under variable partial pressure of solvent (ratio of vapour pressure of solvent over its saturated vapour pressure; $\mathrm{P}_{\text {solvent }} / \mathrm{P}_{\text {sat }}$ hereafter) at a fixed temperature. The sorption and desorption isotherms were carried out with a controlled microbalance system (Dynamic Vapour Sorption DVS-Advantage plus, Surface Measurement System, UK) [5].

Details on the protocol used are presented in table 1 .

Table 1. Experimental details of the protocol used for DVS experiments

\begin{tabular}{|c|c|c|}
\hline $\begin{array}{l}\text { Numerous } \\
\text { of the step }\end{array}$ & Solvent used & $\begin{array}{c}\mathrm{P}_{\text {solvent }} / \mathrm{P}_{\text {sat }}(\%) \\
\text { implement of }+/-10 \%\end{array}$ \\
\hline 1 & Water & $50 \rightarrow 40 \rightarrow \ldots \rightarrow 0$ \\
\hline 2 & $\begin{array}{c}\text { Ethanol or } \\
\text { methanol }\end{array}$ & $0 \rightarrow 10 \rightarrow \ldots \rightarrow 90 \rightarrow 80 \ldots \rightarrow 0$ \\
\hline 3 & Water & $0 \rightarrow 10 \rightarrow \ldots \rightarrow 50$ \\
\hline \multicolumn{3}{|c|}{ Temperature : $20^{\circ} \mathrm{C}$} \\
\hline \multicolumn{3}{|c|}{$\begin{array}{l}\text { Equilibrium criteria for the implementation of } \mathrm{P}_{\text {solvent }} / \mathrm{P}_{\text {sat }} \text { : } \\
\qquad \mathrm{dm} / \mathrm{dt}<0,0005 \% \cdot \mathrm{min}^{-1}\end{array}$} \\
\hline \multicolumn{3}{|c|}{ Maximum time on a $\mathrm{P}_{\text {solvent }} / \mathrm{P}_{\text {sat }}$ step : 2000 mins } \\
\hline \multicolumn{3}{|c|}{ Initial product : $(\mathrm{S})-\mathrm{TUK}, 2 \mathrm{H}_{2} \mathrm{O}$} \\
\hline
\end{tabular}

\subsection{DITA}

The isothermal section at $20^{\circ} \mathrm{C}$ of the ternary phase diagram [(S)-TUK - Methanol - Ethanol] was established with the help of DITA (Discontinuous Isoperibolic Thermal Analysis) measurements (see ref. [6-9] for details on the experimental conditions). This technique is of particular interest when solid phases are efflorescent as in the present study.

\section{Results and discussion}

\subsection{Phases characterization}

\subsubsection{Ethanol solvate}

The structure of the ethanol solvate of (S)-Tenatoprazole potassium salt has been characterized by using singlecrystal X-ray diffraction (figure 2). This structure indicates that its stoichiometry is (S)-TUK, $\mathrm{EtOH}_{2}$. Furthermore, the ethanol molecules play an important role in the crystal cohesion. Indeed, they act as an electrostatic relay between the potassium cation and the tenatoprazole anion [4].

Dynamic Vapour Sorption analyses (DVS) has been carried, at $20^{\circ} \mathrm{C}$, starting from the dihydrate tenatoprazole potassium salt which is the stable phase under ambient atmosphere (figure 3).

The first desolvation step led to the monohydrate, but no anhydrous form could be obtained [10]. Under partial pressure in ethanol, during the sorption, a concomitant dehydration-solvation phenomenon led to the ethanol solvate. Then, the desorption led to an anhydrous form. Finally, under partial pressure in water (up to $50 \%$ ), the stoichiometry of the initial dihydrate has been obtained.

This characterization of the solid vapour equilibria established that:

- The stoichiometry of the ethanol solvate is confirmed (S)-TUK, EtOH ${ }_{2}$.

- The dehydration / solvation phenomenon is reversible.

- The kinetic of phase transformations is slow. More particularly, the evolution from the ethanol solvate towards the anhydrous form is consistent with the crucial role of the solvent molecule in the crystal cohesion [4].

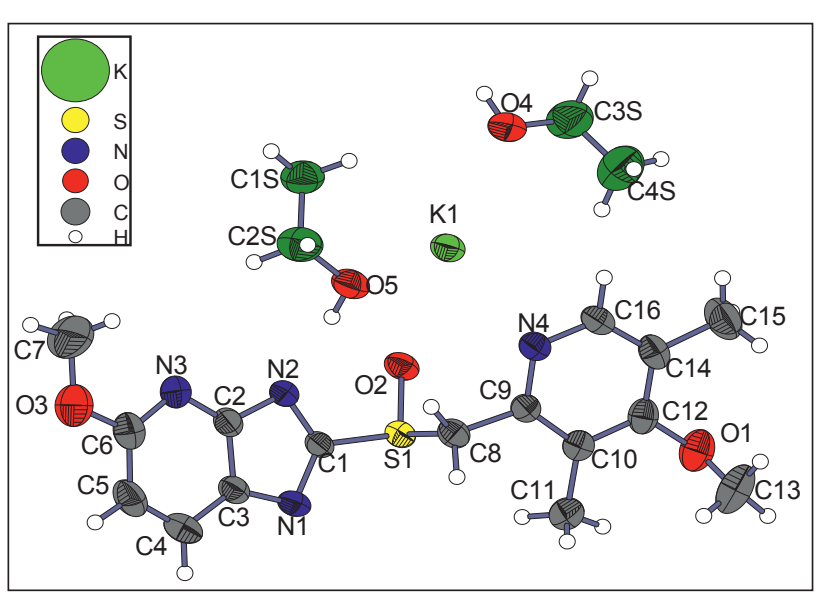

Fig. 2. ORTEP view at 50\% probability (except hydrogen atoms) of the asymmetric unit of [(S)-TUK, $\left.\mathrm{EtOH}_{2}\right]$

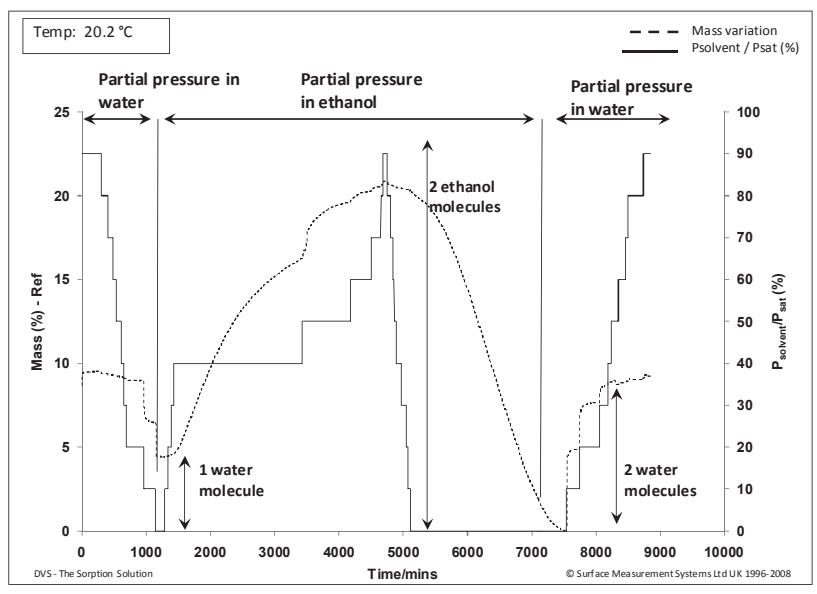

Fig. 3. Sorption desorption isotherms made on (S)-TUK, $2 \mathrm{H}_{2} \mathrm{O}$ at $20^{\circ} \mathrm{C}$ under variable solvent vapour pressure

\subsubsection{Methanol solvate}

Up to now, no single-crystal of this solvate has been obtained. Nevertheless, the experimental XRPD pattern has great similarities with that of the ethanol solvate 
(figure 6). This indicates that the structures of the solvates exhibit extensive similarities.

Dynamic Vapour Sorption analyses (DVS) established that: (figure 4).

- The stoichiometry of the methanol solvate is (S)TUK, $\mathrm{MeOH}_{2}$;

- It presents the same behaviour of the ethanol solvate (reversibility of the desolvationsolvation phenomenon and slow kinetics of transformations).

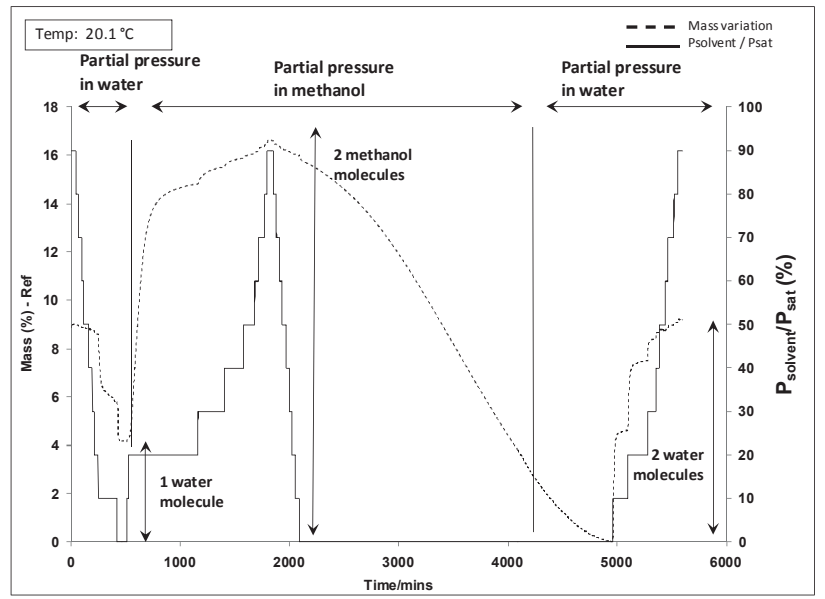

Fig. 4. Sorption desorption isotherms made on (S)-TUK, $2 \mathrm{H}_{2} \mathrm{O}$ at $20^{\circ} \mathrm{C}$ under variable solvent vapour pressure

\subsubsection{Mixed solvate}

Single crystals were obtained by slow evaporation of a methanol / ethanol mixture $(20 / 80 \% \mathrm{w} / \mathrm{w})$ initially saturated in (S)-TUK. The structure indicated that the global stoichiometry of the solid phase is (S)TUK, $\mathrm{MeOH}_{\mathrm{x}}, \mathrm{EtOH}_{2-\mathrm{x}}$ with $\mathrm{x} \approx 1$ (figure 5). This solid presents the same crystal packing as the ethanol solvate and the molecules of ethanol are randomly substituted by those of methanol. This is characteristic of a mixed solvate. It implies that the ethanol solvate and the mixed solvate with $\mathrm{x} \approx 1$ correspond to the same phase. Then, from a thermodynamic point of view, there is a continuous solid solution from ethanol solvate ((S)$\mathrm{TUK}, \mathrm{EtOH}_{2}$ ) up to the composition (S)TUK, $\mathrm{MeOH}_{1}, \mathrm{EtOH}_{1}$ ) [4].

All these structural data (the superimposition of the calculated and experimental patterns (figure 6), comparison of structures [4], cell parameters and space groups (table 2)) and the stoichiometry of isolated solvates seem to be consistent with the existence of a total solid solution between the methanol and the ethanol solvate.

\subsection{Experimental determination of isothermal section at $20^{\circ} \mathrm{C}$.}

In order to establish more accurately the thermodynamic relationship between both solvates, the determination of an isothermal section has been carried out by using in situ XRPD on suspensions and DITA measurements.

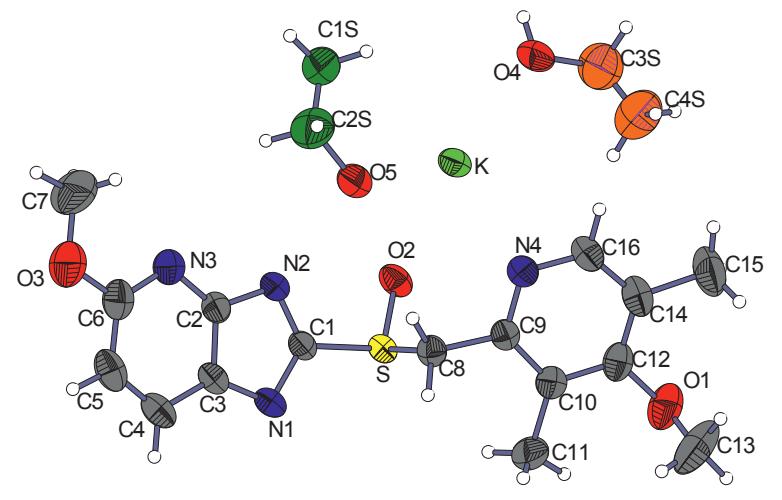

Fig. 5. ORTEP view at the $50 \%$ probability (except hydrogen atoms) of the asymmetric unit of [(S)-TUK, $\left.\mathrm{MeOH}_{\mathrm{x}}, \mathrm{EtOH}_{(2-\mathrm{x})}\right]$ where $\mathrm{x} \approx 1$. The occupancy rates of the terminal methyl groups are $46 \%$ (green) and 54\% (orange)

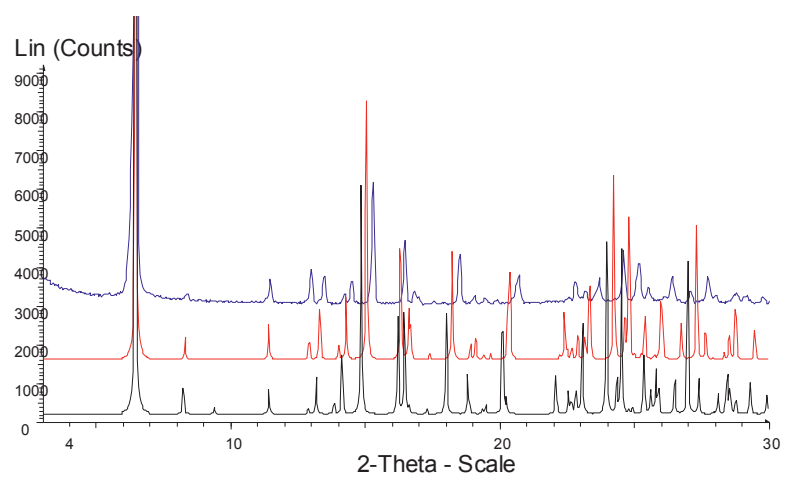

Fig. 6. Superposition of the XRD patterns of the ethanol solvate (bottom, calculated) and the mixed solvate (middle, calculated) and methanol solvate (top, experimental)

Table 2. Crystalline parameters of alcohol solvates of (S)-TUK determined by using SC-XRD or by means of profile matching made on XRPD

\begin{tabular}{|c|c|c|c|}
\hline & (S)-TUK,EtOH ${ }_{2}$ & $\begin{array}{l}\text { (S)-TUK, } \\
\mathrm{MeOH}_{\mathrm{x}} \mathrm{EtOH}_{(2-\mathrm{x})}\end{array}$ & (S)-TUK, $\mathrm{MeOH}_{2}$ \\
\hline & \multicolumn{2}{|l|}{ XRD on single crystals } & $\begin{array}{l}\text { Indexation-Profile } \\
\text { matching }\end{array}$ \\
\hline Empirical formula & $\begin{array}{l}{\left[\mathrm{K}^{+}, \mathrm{C}_{18} \mathrm{H}_{23} \mathrm{~N}_{4} \mathrm{O}_{3} \mathrm{~S}^{-}\right]} \\
2 \mathrm{C}_{2} \mathrm{H}_{5} \mathrm{OH}\end{array}$ & $\begin{array}{l}{\left[\mathrm{K}^{+}, \mathrm{C}_{18} \mathrm{H}_{23} \mathrm{~N}_{4} \mathrm{O}_{3} \mathrm{~S}\right]} \\
\mathrm{C}_{2} \mathrm{H}_{5} \mathrm{OH}, \mathrm{CH}_{3} \mathrm{OH}\end{array}$ & $\begin{array}{l}{\left[\mathrm{K}^{+}, \mathrm{C}_{18} \mathrm{H}_{23} \mathrm{~N}_{4} \mathrm{O}_{3} \mathrm{~S}^{-}\right]} \\
2 \mathrm{CH}_{3} \mathrm{OH}\end{array}$ \\
\hline $\begin{array}{l}\text { Crystalline System } \\
\text { Space Group }\end{array}$ & $\begin{array}{l}\text { Monoclinic } \\
\mathrm{P} 2_{1}\end{array}$ & $\begin{array}{l}\text { Monoclinic } \\
\mathrm{P} 2_{1}\end{array}$ & $\begin{array}{l}\text { Monoclinic } \\
\mathrm{P} 2_{1}\end{array}$ \\
\hline$z, z^{\prime}$ & 2,1 & 2,1 & \\
\hline Cell parameters $(\AA)$ & $\begin{array}{l}a=10.981(1) \\
b=7.705(1) \\
c=14.026(1) \\
\beta=101.50(1)^{\circ}\end{array}$ & $\begin{array}{l}a=10.855(2) \\
b=7.615(1) \\
c=13.950(1) \\
\beta=100.58(1)^{\circ}\end{array}$ & $\begin{array}{l}a=10.70(1) \\
b=7.52(1) \\
c=13.86(1) \\
\beta=99.84(1)^{\circ}\end{array}$ \\
\hline Cell volume $\left(\AA^{3}\right)$ & $1162.8(2)$ & $1133.4(2)$ & 1099(1) \\
\hline Reliability factor $\mid>2 \sigma(I)$ & $\begin{array}{l}R_{1}=3.57 \% \\
\mathrm{wR}_{2}=6.34 \%\end{array}$ & $\begin{array}{l}R_{1}=3.97 \% \\
\mathrm{wR}_{2}=10.54 \%\end{array}$ & $\begin{array}{l}R_{w p}=4.07 \% \\
R p=3.02 \%\end{array}$ \\
\hline $\begin{array}{l}\text { Absolute structure Flack } \\
\text { parameter }\end{array}$ & $0.07(4)$ & 1 & 1 \\
\hline
\end{tabular}

\subsubsection{XRPD on suspensions}

Suspensions of (S)-TUK in different methanol / ethanol mixtures have been prepared (circa $0.3 \mathrm{~g} \cdot \mathrm{mL}^{-1}$ ). Solid phases, in thermodynamic equilibrium with their saturated solution, have been analysed in situ by using 
XRPD (figure 7). By means of profile matching, the volume of unit cells has been determined for each solid in suspensions (figure 8).

Between compositions $0 / 100$ and $30 / 70 \% \mathrm{w} / \mathrm{w}, \mathrm{a}$ continuous shift of diffraction peaks towards high angles is observed inducing a continuous decrease of the unit cell volume. These evolutions are consistent with a solid solution: the decrease of the volume cell is probably due to the exchange between the solvent molecules, given that the methanol molecules are smaller than the ethanol molecules. It is noteworthy that the calculated XRPD pattern and, by consequence, the unit cell volume, of the mixed solvate $\left((\mathrm{S})-\mathrm{TUK}, \mathrm{MeOH}_{1}, \mathrm{EtOH}_{1}\right)$ is consistent with that of the solid obtained in the methanol / ethanol mixture $20 / 80 \% \mathrm{w} / \mathrm{w}$ (see 3.1.3).

Between $50 / 50$ and $100 / 0 \% \mathrm{w} / \mathrm{w}$, no shift of diffraction peaks was highlighted and the volume of the unit cell is constant. Nevertheless, a broadening of the XRPD peaks can be observed with the increase of the proportion in ethanol solvent.

This discontinuity indicates that the phase crystallizing in this range of concentration is the same for all the suspensions. There is then no adaptation of the unit cell to exchange solvent molecules.

However, the volume calculated for the composition $40 / 60 \% \mathrm{w} / \mathrm{w}$ presents a value belonging neither to the continuous decrease nor to the plateau.

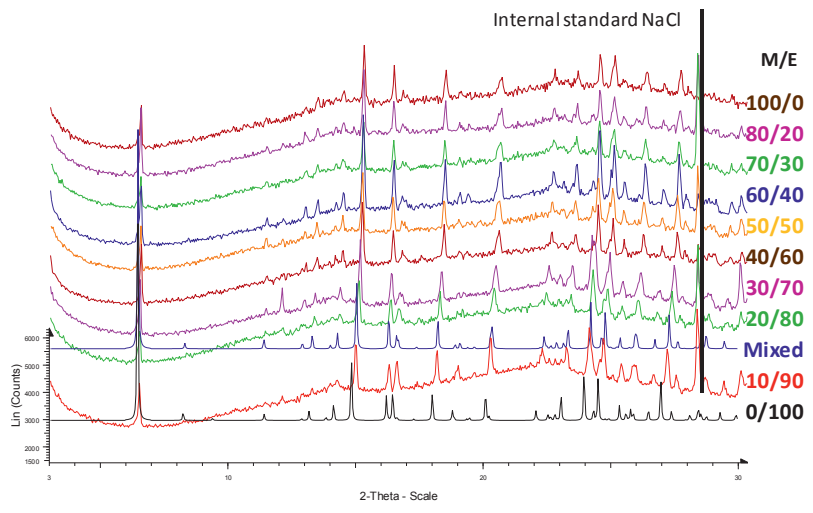

Fig. 7. Superposition of the in situ XRPD patterns as a function of the composition of the mother liquor (methanol / ethanol \%w/w)

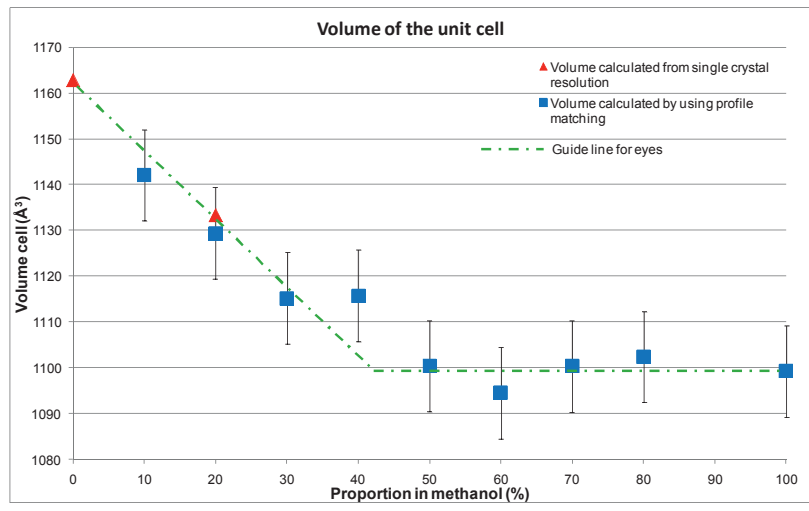

Fig. 8. Unit cell volume evolution as a function of the composition of the mother liquor

All these experiments are in contradiction with the existence of a total solid solution between methanol and ethanol solvate. Indeed, the discontinuity observed in the evolution of the unit cell volume as a function of the composition of the mother liquor is consistent with the existence of two different biphasic domains (figure 9b):

- One associating (S)-TUK, $\mathrm{MeOH}_{2}$ and its saturated solution,

- The other one associating a partial solid solution issued from (S)-TUK, EtOH 2 and a saturated solution.

It has to be noticed that the existence of a necessary three phase domain has not been clearly observed, probably due to its narrow width in this range of composition (figure 9b) (circa $0.3 \mathrm{~g} \cdot \mathrm{mL}^{-1}$ for the suspensions). The original behaviour observed for solid crystallised for the composition $40 / 60 \% \mathrm{w} / \mathrm{w}$ could be due to its location in this three phase domain.

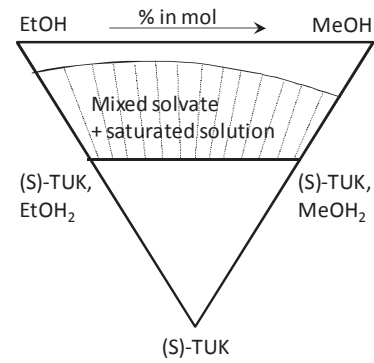

Fig. 9a. Hypothetical isothermal section showing a total solid solution between solvates

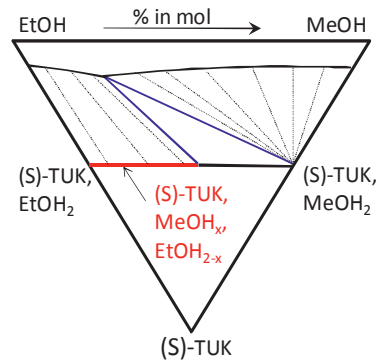

Fig. 9b. Hypothetical isothermal section showing a partial solid solution between solvates

\subsubsection{Solubility curve / DITA measurements}

The solubility curve has been determined with DITA measurements. It shows an inflexion for the methanol / ethanol mixture $30 / 70 \% \mathrm{w} / \mathrm{w}$ composition which indicates the presence of a three phase domain (figure $9 \mathrm{~b}$ and 10).

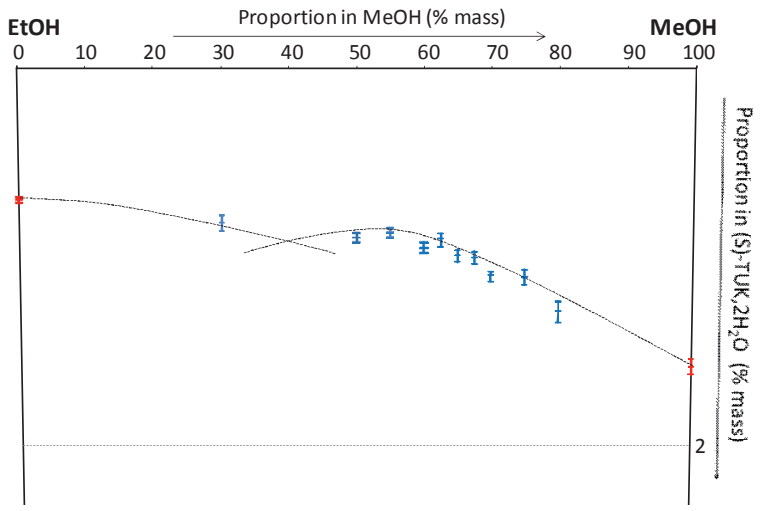

Fig. 10. Zoom of the experimental isothermal section at $20^{\circ} \mathrm{C}$ of the system [(S)-TUK / Methanol / Ethanol].

Moreover, the DITA measurement carried out from the methanol / ethanol mixture $30 / 70 \% \mathrm{w} / \mathrm{w}$ shows two slope disruptions (figure 11). As the final mixture is an homogeneous liquid, the first disruption corresponds to the limit between a three and a two phase domain and the 
second one to the boundary between a two phase domain and the homogeneous solution.

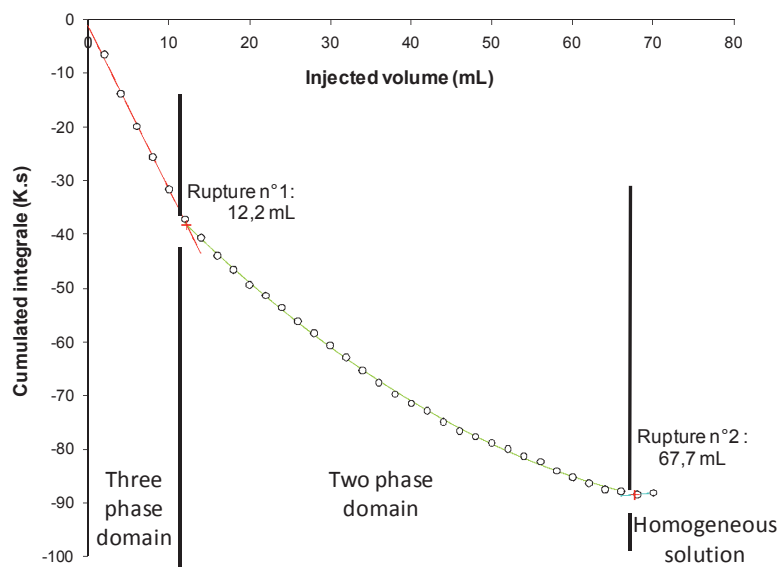

Fig. 11. DITA measurements carried out at $20^{\circ} \mathrm{C}$, solvent composition $30 / 70 \% \mathrm{w} / \mathrm{w}$

Therefore, owing to the results collected on this system, an experimental isothermal section at $20^{\circ} \mathrm{C}$, can be proposed (figure 12).

This isothermal section exhibits two biphasic domains and a single triphasic domain. So, an unexpected partial solid solution between ethanol and methanol solvates exists from (S)-TUK, EtOH $\mathrm{H}_{2}$ up to a mixed composition $(>50 \%)$ which has to be precisely determined. The methanol solvate is a different phase from this solid solution.

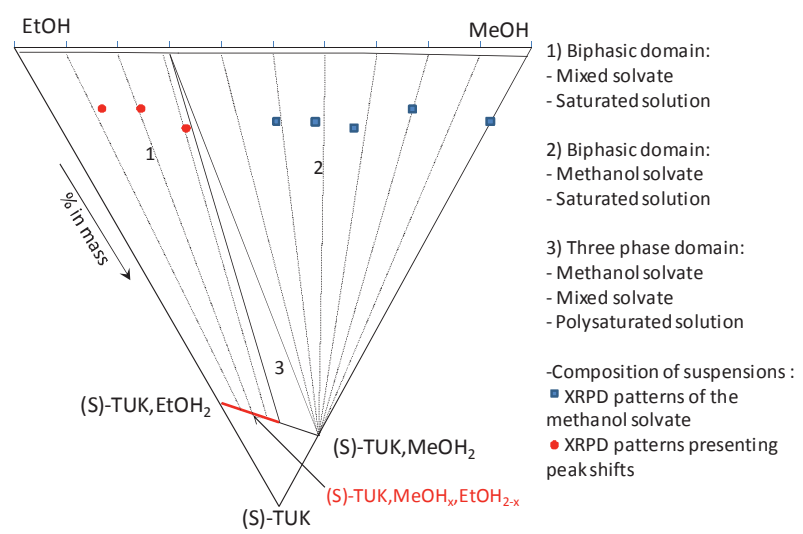

Fig. 12. Experimental isothermal section at $20^{\circ} \mathrm{C}$ of the system [(S)-TUK / Methanol / Ethanol] mass fraction

\section{Conclusion}

In the system [(S)-TUK / Methanol / Ethanol], ethanol and methanol solvates present great similarities likely to postulate a possible complete solid solution between them:

- They have the same stoichiometry,

- They crystallise with the same space group, the same crystal packing and the solvent play a similar role in the structural cohesion,

- A mixed solvate ((S)-TUK, $\left.\mathrm{MeOH}_{1}, \mathrm{EtOH}_{1}\right)$ resulting from the random substitution of ethanol and methanol molecule in the structure was characterized.

Nevertheless, the study of heterogeneous equilibria in the isothermal section at $20^{\circ} \mathrm{C}$ highlighted a different behaviour. Indeed, structural (XRPD made on suspensions) and thermal (DITA) analyses indicate the existence of a partial solid solution only, stemming from the ethanol solvate. As a consequence, a three phase domain associating (S)-TUK, $\mathrm{MeOH}_{2}$, a saturated solution and (S)-TUK, $\mathrm{MeOH}_{\mathrm{x}}, \mathrm{EtOH}_{(2-\mathrm{x})}$ is strongly suspected.

Further investigations are needed in order to describe thoroughly the solid solution between solvates. In particular, the quantification of solvent molecules in the solid phases by thermal or DVS analyses could improve the description of this isothermal section.

\section{References}

1. A. Cohen, F. Schutze, S. Charbit, F. Martinet, H. Ficheux, M. Homerin, WO. Patent 2006/005853

2. A. Cohen, S. Charbit, F. Schutze, S. Bernad, G. Tauvel, M.-N. Petit, G. Coquerel, WO. Patent 2008/081104

3. G. Coquerel, in Topics in Current Chemistry (Novel Optical Resolution Technologies), Chap. 1, pp. 151, ISSN: 0340-1022 (Springer GmbH, 2007)

4. G. Tauvel, M. Sanselme, S. Coste-Leconte, S. Petit, G. Coquerel, J. Mol. Struct., 936, 60 (2009)

5. N. Couvrat, Y. Cartigny, G. Coquerel, Influence of solid vapour equilibria on the stability of organic solids, in the $X X X V$ JEEP - 35th Conference on Phase Equilibria proceedings, 00012, 2009

6. P. Marchand, L. Lefèbvre, L. Courvoisier, G. Perez, J. J. Counioux, G. Coquerel, J. Phys. IV France,11, 115 (2001)

7. P. Marchand, L. Lefèbvre, G. Perez, J. J. Counioux, G. Coquerel, J. Therm. Anal. Cal., 68, 37 (2002)

8. P. Marchand, L. Lefèbvre, F. Querniard, P. Cardinaël, G. Perez, J. J. Counioux, G. Coquerel, Tetrahedron:Asymmetry, 15, 2455 (2004)

9. P. Marchand, L. Lefèbvre, G. Perez, J.J. Counioux, G. Coquerel,. J. Therm. Anal. Cal., 68, 37 (2002)

10. G. Tauvel, Étude de composés salins du Ténatoprazole. Accès aux énantiomères par cristallisation préférentielle. $\mathrm{PhD}$ Thesis, University of Rouen, (2008) 